\title{
REVIEW
}

\section{Prostaglandins in aquatic fauna: a comprehensive review}

\author{
Bruce Ruggeri \& Carolyn A. Thoroughgood
}

College of Marine Studies, University of Delaware, Newark, Delaware 19716, USA

\begin{abstract}
The presence and role of prostaglandin moieties in aquatic fauna have been a subject of study for only the last $15 \mathrm{yr}$. This review discusses the occurrence and physiological functions of these autocoids in a broad range of marine and freshwater fauna. The role of prostaglandins of the $\mathrm{E}$ and $\mathrm{A}$ series, in particular, in osmoregulation and mineral transport has been studied in several marine invertebrate phyla demonstrating analogy to the roles of these compounds in renal hemodynamics, diuresis, and electrolyte balance in higher terrestrial vertebrates. Prostaglandins of the F series have been implicated in the spawning and hatching processes in a number of marine invertebrates. These findings are discussed in parallel to the body of evidence implicating prostaglandins of the $E$ and $F$ series in the reproductive physiology and spawning behavior of a number of teleosts studied. Many of the advances leading to the present state of knowledge of eicosanoid biology in marine and freshwater fauna stem from advances in analytical methodology for the quantitative and qualitative study of these bioactive compounds. Despite these advances, progress in the field of eicosanoid biology in aquatic fauna has proceeded at a slow pace compared to that in terrestrial fauna, leaving significant gaps in current understanding of the roles of these compounds in numerous aquatic species. Continued research in this field holds promise for the marine biologist and biochemist, as well as the mariculturist, if ongoing attempts to monitor and control the cultivation and reproduction of certain aquatic species is to be successful in the future.
\end{abstract}

\section{INTRODUCTION}

Within the past $25 \mathrm{yr}$, perhaps the most significant advances made in lipid chemistry and pharmacology have been those regarding the autocoids - the group of pharmacologically-active eicosanoids consisting of prostaglandins, thromboxanes, prostacyclins, and leukotrienes. Excellent reviews have been published describing discovery, nomenclature, biochemistry, and pharmacology of these hormone-like compounds derived from $\omega 6$ and $\omega 3$ polyenoic acids by complex enzymatic oxidative processes (Van Dorp et al. 1964, Bergstrom et al. 1968, Samuelsson et al. 1975, Karim 1976, Needleman et al. 1979, Robert \& Newton 1982). The present degree of interest in this class of compounds is reflected by the number of publications in this field; a library computer search revealed that over
12,500 articles on prostaglandin-related experimentation alone have appeared in the biomedical literature between 1981 and 1984 .

Prostaglandin synthesis is ubiquitous in mammalian systems (Bergstrom et al. 1968, Kirton 1977, Demes 1979). These compounds appear to be natural constituents of almost all mammalian tissues, the notable exception being the red blood cell (Kennedy 1982). The compounds are not stored but synthesized rapidly in response to physiological or biochemical stimuli; the renal medulla and seminal vesicles being the most active sites of synthesis (Travis 1980). Like hormones, they are active at low concentrations $\left(10^{-11}\right.$ mole $\left.\mathrm{l}^{-1}\right)$ (Kennedy 1982) and demonstrate a high degree of chemical specificity in their mode of action. Upon release into peripheral circulation, however, they are rapidly metabolized, particularly by enzymes in the 
renal cortex, lungs, and liver (Kirton 1977, Travis $1980)^{\circ}$. Consequently, many analytical systems developed for prostaglandin, thromboxane and prostacyclin research have been applied to the chemically more stable metabolites of these compounds. (For excellent reviews see: Salmon \& Karim 1976, Granstrom \& Kindahl 1978, Lands \& Smith 1982).

Despite the abundance of Iiterature describing the occurrence and physiological roles of prostaglandins in mammalian systems, comparatively little attention has been focused on their occurrence and biological function(s) in non-mammalian aquatic species, especially the marine invertebrates. It is the purpose of this review to examine the literature available on the role of the prostaglandins in aquatic fauna.

\section{PROSTAGLANDINS IN AQUATIC INVERTEBRATES}

The earliest report of the occurrence of prostaglandins in marine invertebrates was the discovery of 15 epi-prostaglandin $\mathrm{A}_{2}$ and its acetate methyl ester in the gorgonian Plexaura homomalla (Esper) native to the Caribbean region (Weinheimer \& Spraggins 1969). The compounds, identified by high resolution mass spectrometry, were present in the air-dried cortex of the coral extract at levels of $0.2 \%\left(15-e p i-A_{2}\right)$ and $1.3 \%$ (diester). These compounds possessed the nonmammalian $\mathrm{R}$ configuration at $\mathrm{C}_{15}$ and lacked the vasodilatory effect of the mammalian $\mathrm{PGA}_{2}$ in vivo. Similar findings were reported by others (Light \& Samuellson 1972) for the same species. Bundy et al. (1972) demonstrated that these inactive compounds could be chemically modified to yield biologically active products.

Schneider et al. (1972) subsequently determined that Plexaura homomalla also contained esterified derivatives of (15-S)-PGA PA $_{2}$ and (15-S)-PGE 2 identical in chemical and biological properties to mammalian prostaglandins. In some corals, both (15-R)- and (15-S)prostaglandins were found (Schneider et al. 1972). Bundy et al. (1972) described the synthesis of the primary prostaglandins $\mathrm{PGE}_{2}$ and $\mathrm{PGF}_{2}$ a from (15-R) and (15-S)-PGA .

These cumulative findings served to reveal an abundant marine source of natural prostaglandins suitable for conversion to pharmacologically active compounds. The physiological role(s) these gorgonian prostaglandins play, however, still remains obscure.

\footnotetext{
- Notable exceptions to this fact are prostacyclin $\left(\mathrm{PGI}_{2}\right)$ and prostaglandin $A_{2}$. These may act as hormones in the true sense as they are not metabolized upon transit through the pulmonary circulation (Demes 1979, Kennedy 1982)
}

Christ \& Van Dorp (1972) examined the occurrence and activity of prostaglandin biosynthesis throughout the animal kingdom, surveying a range of terrestrial and aquatic phyla. Homogenates of animal tissues were incubated with cis- $\left(8,9,11,12,14,15-{ }^{3} \mathrm{H}_{6}\right)$ eicosatrienoic acid and the enzymatic products examined spectrophotometrically and by gas chromatographyelectron capture. Among the marine invertebrates examined were species of Anthoplexaura (horny coral), Cyanea (jellyfish), Mytilis (mussel) and Homarus (lobster). Activities were low in each case $\left(<4 \%\right.$ substrate conversion) for prostaglandins $E_{1}, B_{1}$, and $F_{1} \alpha$, with the highest activity found in the gill tissues of fish, mussel, and lobster (Christ \& Van Dorp 1972). These same tissues contained arachidonic acid as well, although the presence of this substrate was not always accompanied by prostaglandin synthesis. The analyses suggested that prostaglandin synthestase activity may be by a tissue-specific occurrence rather than a species-specific phenomenon. The physiological significance of this specificity is still speculative, but in view of the high activity found in mammalian lung, gill tissues of fishes, molluscs and arthropods, in frog bladder (Christ \& Van Dorp 1972, Nomura \& Ogata 1976) and in mammalian renal medulla (Keuhl et al. 1976, Demes 1979, Travis 1980, Kennedy 1982), these compounds may play a role in the regulation of mineral and/or water tranport in a range of species (Christ \& Van Dorp 1972, Graves \& Dietz 1979, Freas \& Grollman 1980).

This hypothetical role in vivo gains support in view of subsequent studies (Nomura \& Ogata 1976, Ogata et al. 1978, Freas \& Grollman 1980). In a systematic survey of a number of animal phyla, Nomura \& Ogata (1976) demonstrated the presence of prostaglandin $E_{2}$ in mussel, scallop, crawfish, blue-crab, sea anenome, and sea-squirt, although the levels were very low as determined by bioassay. A subsequent study (Ogata et al. 1979) on a number of the same organisms demonstrated a very low $(<8 \%)$ conversion of ${ }^{3} \mathrm{H}$-labelled eicosatrienoic acid into prostaglandins $E_{1}$ and $F_{1} \alpha$. In this and the previous study reported, however, moderate acivity was found in the gill tissue of each species examined. The most convincing evidence for the role of prostaglandins in osmoregulation was that of Freas \& Grollman (1980) in their work with the mollusk Modiollus demissus, a euryhaline osmoconformer. It was demonstrated that significant increases in the synthesis and release of immunoreactive $\mathrm{PGE}_{2}$ occur in this bivalve, especially in gill tissue, in response to hypoosomotic stress and magnesium-free seawater. Significantly, prostaglandin synthesis was enhanced by exogenous arachidonic acid and inhibited by the cyclooxygenase inhibitors, indomethacin and aspirin (Freas \& Grollman 1980). 
These cumulative findings would seem to suggest that the E-prostaglandins and their dehydration products, PGA, play a definite role in osmoregulation and water transport in marine invertebrates analogous to their role in renal hemodynamics, diuresis, and electrolyte balance in higher vertebrates and humans (Keuhl et al. 1976, Demes 1979, Travis 1980, Kennedy 1982).

There are but a few reports regarding the role of prostaglandins in the reproduction of aquatic invertebrates, in contrast to that of both aquatic and terrestrial vertebrate species.

In their studies of the chemical regulators of reproduction and ontogenesis in abalone (Haliotis rufescens), Morse et al. (1977) determined that the addition of hydrogen peroxide to seawater induces synchronous spawning in gravid abalones of both sexes. Similar synchronicity was observed for gravid mussels (Mytilus californianus) as well (Morse et al. 1976). These effects were believed to be due to activation of cyclooxygenase by a specific electronically activated form of oxygen (e.g. hydroperoxy free radical, HOO or peroxy diradical $\cdot 00$-) (Morse et al. 1977) resulting in the synthesis of the highly reactive prostaglandin endoperoxides, the precursors to both prostaglandins and thromboxanes. This peroxide-induced spawning was blocked by aspirin, as well as catalase and mercaptoethanol, the latter 2 agents destroying the peroxide. These findings, and the high concentrations of cyclooxygenase (100 times that in rabbit prostrate) in eggs and gonads of abalone, suggest a role of the endoperoxides and/or prostaglandins in spawning. In addition, the synthesis of cyclooxygenase in eggs may control both fertilization and ontogenesis (Morse et al. 1976).

Subsequent studies substantiated a possible role of prostaglandins in marine bivalve reproduction. Ono et al. (1982) measured ovarian $\mathrm{PGF}_{2} \alpha$ levels in the Japanese oyster Crassostrea gigas (Thurberg) using radioimmunoassay. Ovarian $\mathrm{PGF}_{2} \alpha$ levels remained at a relatively constant $7 \mathrm{ng} \mathrm{g}^{-1}$ wet tissue during early sexual maturation, but peaked at $25 \mathrm{ng} \mathrm{g}^{-1}$ during late sexual maturation just prior to spawning. These marked increases prior to ovulation parallel the effects observed in higher vertebrates and fish (Ogata et al. 1979, Cetta \& Goetz 1982, Stacey \& Goetz 1982), as to be discussed.

Clare et al. (1982) extracted and purified the 'hatching substance' from adult barnacles Balanus balanoides, and identified it as a prostaglandin F compound upon chromatographic analysis, bioassay, and gas chromatography mass spectrometry. It was demonstrated (Clare et al. 1982) that extracts from Plexaura homomalla possessed identical chromatographic and biological activities as the isolated hatching subst- ance; the latter lost its activity below $\mathrm{pH} 3$ and its synthesis was blocked by aspirin.

The role of the F-prostaglandins in particular in spawning and hatching is feasible in view of their potent contractile activity and their reported role in follicular rupture and luteolysis in a number of vertebrate species (Samuelsson et al. 1975. Demes 1979, Kennedy 1982, Stacey \& Goetz 1982). As hatching and spawning are initiated by rhythmic movements of embryonic and gonadal muscle, respectively, a role for PGF compounds in bivalve reproduction gains credibility. Far more research in a variety of species and genera, however, is necessary to elaborate the precise role(s) of these compounds and their regulation.

In the most recent report available, Levine \& Kobayashi (1983) analysed 4 invertebrate species for $\mathrm{PGE}_{2}$, $\mathrm{PGF}_{2} \alpha$, 6-keto-PGF ${ }_{2} \alpha$, thromboxane $B_{2}$, and the lipoxygenase product, 12-HETE by high-performance liquid chromatography and radioimmunoassay. Organic extracts of Terpios zeteki (phylum Porifera), Aplysia californica and Helix aspersa (phylum Mollusca) and Arbacia (sea urchin, phylum Echinodermata) were analysed. These species demonstrated the presence of immunoreactive compounds against antisera for prostaglandins, thromboxane, and 12-HETE derived from arachidonic acid. Analysis by immunochromatography (HPLC), however, demonstrated that these compounds differed in their retention times from the immunologically homologous eiconsanoids derived from arachidonic acid (Levine \& Kobayashi 1983). These authors concluded that these immunoreactive agents possess antigenically-recognizable features in their ring structure, although they may have been derived from arachidonic acid metabolites or polyunsaturated moieties such as $20: 5 \omega 3$ or $22: 5 \omega 3$, thus accounting for their non-mammalian chromatographic behavior. These findings await confirmation by gas chromatography-mass spectrometry. Studies of this nature demonstrate well the heterogeneity in marine invertebrate lipid composition (Joseph 1982) making accurate identification of prostaglandins both time-consuming and difficult.

\section{PROSTAGLANDINS IN AQUATIC VERTEBRATES}

The earliest report of the occurrence of prostaglandins in aquatic vertebrates was that of Christ \& Van Dorp (1972). Studies of the genera Cyprinus (carp), Tinica (tench), and Salmo (trout) demonstrated moderate prostaglandin synthetase activity ( 3 to $9 \%$ ) in the gill tissues of these species compared to visceral prostaglandin levels. Subsequent studies confirmed and extended these findings. Nomura \& Ogata (1976) reported that prostaglandin-like compounds exist in 
the semen and testes of teleosts, and previously isolated prostaglandin $E_{2}$ (by bioassay, TLC, GL-MS) in the gastrointestinal tract of the leopard shark Triakis scyllia (Ogata \& Nomura 1975j. In this, the first report of prostaglandins in Elasmobranchs, levels of $2.5 \mu \mathrm{g}$ $\mathrm{g}^{-1}$ wet weight of tissue were detected. In addition, arachidonic acid was found to constitute $17.2 \%$ of the total fatty acids of the GI tract of T. scyllia (Ogata \& Nomura 1975). Later studies (Nomura \& Ogata 1976, Ogata et al. 1979) reported high nanogram levels of prostaglandin $\mathrm{E}_{3}$ in the GI tract, air bladders, gills, and heart of carp, sheatfish, and leopard shark; levels of $\mathrm{PGE}_{3}$ in ovaries, testes and brain were much lower (Nomura \& Ogata 1976).

The presence of a novel prostaglandin $\mathrm{C}-22 \mathrm{~F}_{4} \mathrm{a}_{\text {, }}$ derived from docosahexanoic acid in trout gill tissue was reported by Mai et al. (1981). Subsequent mass spectrometric studies by German et al. (1983) demonstrated that this compound was a trihydroxylated polyenoic fatty acid derived from lipoxygenase activity in this species.

Despite these findings in a number of species, the exact role(s) of these compounds was unknown, although some involvement in osmoregulation or smooth muscle motility was speculated (Christ \& Van Dorp 1972). Presently, the role(s) of these compounds in those tissues examined is still uncertain.

In contrast, in the past decade a rather substantial number or reports have appeared regarding a physiological role of prostaglandins in spawning behavior and reproductive function in teleosts (Stacey \& Liley 1974, Jalabert \& Szollosi 1975, Stacey \& Pandey 1975, Singh \& Singh 1976, Stacey 1976, Bouffard 1979, Ogata et al. 1979, Stacey \& Peter 1979, Stacey 1981, Cetta \& Goetz 1982, Stacey \& Goetz 1982, Goetz \& Cetta 1983). An excellent review of the role of prostaglandins in piscine reproduction has been published by Stacey \& Goetz (1982). The present article will not attempt to duplicate their work, but in accomplishing the objectives of this comprehensive review, the chronology of findings leading to the present knowledge of prostaglandin function in teleosts will be surveyed.

A role for prostaglandins in ovulation and spawning behavior has been substantiated by a number of in vitro and in vivo studies.

Jalabert \& Szollosi (1975) demonstrated that rainbow trout Salmo gairdneri follicles matured in vivo could be induced to ovulate in vitro upon exposure to $\mathrm{PGF}_{2} \alpha$ (1 to $5 \mu \mathrm{g} \mathrm{ml}^{-1}$ ). This response was a result of the contractile effects of $\mathrm{PGF}_{2} \alpha$ on the smooth muscle cells of the theca; $\mathrm{PGE}_{2}$ was ineffective in this regard. These findings were subsequently confirmed by in vitro studies with brook trout Salvelinus fontinalis oocytes exposed to $\mathrm{PGF}_{2} \alpha$ (stimulatory) and $\mathrm{PGE}_{1}$ (inhibitory) (Goetz et al, 1982). In contrast, Goetz \& Theofan (1979) demonstrated that indomethacin-blockade of steroidinduced in vitro ovulation of perch Perca flavescens oocytes could be restored by both $\mathrm{PGF}_{2} \alpha$ and $\mathrm{PGE}_{1}$, $\mathrm{PGE}_{2}$ (the latter most effective), suggesting that the effect of a particular prostaglandin in vitro may be a species-specific phenomenon.

More convincing evidence for the role of prostaglandins in ovulation and ovarian activity was provided by in vivo studies in a number of species.

Stacey \& Pandey (1975) were first to observe in goldfish Carassius auratus that ovulation induced in vivo by human chorionic gonadotropin could be blocked by indomethacin and restored by exogenous prostaglandins. Prostaglandin $\mathrm{E}_{2}, \mathrm{PGE}_{1}$, and $\mathrm{PGD}_{2} \alpha$ were equally effective in restoring ovulation in goldfish when administered $11 \mathrm{~h}$ post-gonadotropin injection but not earlier. Stacey \& Goetz (1982) suggested that prostaglandins synthesized in the ovary may act at the ovarian level prior to follicle rupture to trigger ovulation. Ogata et al. (1979) postulated a similar mechanism to explain the rise in ovarian $\mathrm{PGF}_{2} \alpha$ observed following gonadotropin-induced ovulation in the pond loach Misgurnus anguillicaudatus. Levels of $\mathrm{PGF}_{2} \alpha$ increased 3 -fold at $12 \mathrm{~h}$ post-gonadotropin treatment. In studies with naturally ovulating brook trout (Goetz \& Cetta 1983) and pituitary-induced ovulating trout (Cetta \& Goetz 1982), it was determined that significant increases in plasma and ovarian PGF levels occur by the completion of ovulation and remained significantly elevated $24 \mathrm{~h}$ post-ovulation. In naturally ovulating trout, levels of PGF remained significantly elevated 5 to $7 \mathrm{~d}$ post-ovulation; these elevated plasma and ovarian PGF levels could be depressed by indomethacin treatment. These findings substantiated the earlier work of Bouffard (1979) in demonstrating both high PGF levels in ovarian fluid of goldfish and significantly elevated plasma PGF levels only at the completion of ovulation. Bouffard (1979) speculated that elevated post-ovulatory PGF levels may be dependent on the presence of ovulated eggs within the lumen. In addition to the role of PGF in follicle rupture and ovulation, Cetta \& Goetz (1982) observed that ovarian PGE levels fall prior to and during ovulation. The inverse relation between PGF and PGE levels in ovulating and post-ovulatory trout may be critical in the whole process, especially in view of previous findings (Goetz et al. 1982) that PGE inhibited in vitro ovulation of Salvelinus fontinalis oocytes.

In addition to their activity at the ovarian level directly, there have been reports that prostaglandins may act as mediators to control ovulation at the hypothalmic or pituitary level (Singh \& Singh 1976). Administration of $\mathrm{PGE}_{1}$ and $\mathrm{PGF}_{2} \alpha$ was $90 \%$ effective in inducing ovulation within $7 \mathrm{~d}$ in sham-hypophysectomized fresh-water catfish Heteropneustes fossilis 
(Singh \& Singh 1976). These compounds stimulated ovarian activity and pituitary and serum gonadotropin levels. Singh \& Singh (1976) postulated that prostaglandins may act directly on the pituitary or hypothalmus to trigger gonadotropin secretion resulting in an increase in ovarian activity and ovulation.

The role of prostaglandins in the spawning behavior of fish has been studied primarily in goldfish (Stacey \& Liley 1974, Stacey 1976, Stacey \& Peter 1979, Stacey 1981, Stacey \& Goetz 1982). These studies have demonstrated that the stimulatory effect on female spawning behavior of ovulated eggs within the lumen is mediated by prostaglandins. Stacey \& Liley (1974) and Stacey (1976) observed that indomethacin injection $10 \mathrm{~h}$ prior, or coincident with, the deposition of ovulated eggs in the ovarian lumen inhibits the onset of spawning. Similarly, spawning behavior ceases within minutes of indomethacin injection (Stacey 1976) but can be restored by injection of $\mathrm{PGF}_{2} \alpha$ and to a lesser extent $\mathrm{PGE}_{2}$. Spawning behavior can likewise be triggered by prostaglandin injection alone in goldfish lacking ovulated eggs (Stacey 1976, Stacey \& Peter 1979. Stacey 1981) or the external cues requisite for spawning (Stacey 1981). These studies suggest that prostaglandins may act as endogenous messengers 'ovulation detectors' - to synchronize sexual behavior with oocyte development in order to insure fertilization.

The studies of several investigators (Stacey \& Peter 1979, Stacey 1981, Stacey \& Goetz 1982) suggest that ovarian prostaglandins may act centrally as potent short-latency, short-duration stimuli on the brain in order to promote female spawning behavior. Levels of $\mathrm{PGF}_{2} \alpha$ as low as $10 \mathrm{ng} \mathrm{g}^{-1}$ injected into the preoptic recess of the third ventricle were far more effective in initiating spawning behavior than injections by other routes (Stacey \& Peter 1979).

Stacey (1981) demonstrated that male goldfish preferred prostaglandin stimulated females. In addition, male fish injected with $\mathrm{PGF}_{2} \alpha$ could likewise be induced to spawn.

As noted by Stacey (1981) and Stacey \& Goetz (1982) prostaglandins may mediate the stimulatory effects of ovulated eggs on spawning activity in a number of oviparous teleosts including Pacific herring Clupea harengus pallasi, rainbow trout Salmo gairdneri, pond loach Misgurnus anquillicaudatus, and three-spine stickleback Gasterosteus aculeatus.

\section{CONCLUSIONS}

Research directed at determining the presence and functions of prostaglandins in aquatic fauna offers great promise for a number of reasons.
The paucity of research done with marine invertebrates illustrate the large gap in present knowledge of the nature and role of these compounds in a large number of marine fauna. The expense of these compounds available commercially should serve as an impetus to the natural products chemist to locate abundant natural sources of prostaglandins. As the case for Plexaura homomalla, marine fauna of little or no commercial use may serve as novel sources of these pharmacologically active compounds. Secondly, understanding the role these compounds serve in the life cycle of numerous invertebrate and vertebrate fauna is of practical concern not only to the marine physiologist or biochemist, but for the commerical hatchery and mariculturist as well. Research directed at understanding the role of prostaglandins in piscine reproduction has been fruitful; such research must be directed at a larger number of teleosts, as well as marine invertebrates, if attempts to control and monitor spawning and hatching behavior of commercially valuable species is to be successful.

Aside from their reproductive role, little is known on the role of prostaglandins in areas such as osmoregulation, temperature adaption, and vascular physiology in marine and freshwater species.

Advances in methodology and analysis of prostaglandins and related compounds have been largely responsible for the breakthroughs in our current understanding of their roles in mammalian systems in both health and disease. Applications of these methods to aquatic species may prove equally fruitful to the marine scientist.

\section{LITERATURE CITED}

Bergstrom, S., Carlson, I. A., Weeks, J. R. (1968). The prostaglandins: a family of biologically-active lipids. Pharmaco. Rev, 20: 1-48

Bouffard, R. E. (1979). The role of prostaglandins during sexual maturation, ovulation, and spermiation in the goldfish, Carassius auratus. M. Sc. thesis, Univ, of British Columbia, Vancouver, Canada

Bundy, G. L., Schneider, W. P., Lincoln, F. H., Pike, J. E. (1972). The synthesis of prostaglandins $E_{2}$ and $F_{2} a$ from (15-R)- and (15-S)-PGA . J. Am. chem. Soc. 94: 2123-2124

Cetta, F., Goetz, F. W. (1982). Ovarian and plasma prostaglandin $E$ and $F$ levels in brook trout (Salvelinus fontinalis) during pituitary-induced ovulation. Biol. Reprod. 27: 1216-1221

Christ, E. J., Van Dorp, D. A. (1972). Comparative aspects of prostaglandin biosynthesis in animal tissues. Biochim. biophys. Acta 270: 537-545

Clare, A. S., Walker, G., Holland, D. L., Crisp, D. J. (1982). Barnacle egg-hatching: a novel role for a prostaglandinlike compound. Mar. Biol. Lett. 3: 113-120

Demes, L. M. (1979). The pharmacology, physiology, and pathology of prostaglandins in human disease. In: Albertini et al. (ed.) Radioimmunoassay of drugs and hormones 
in cardiovascular medicine. Elsevier-North-Holland Biomedical Press, Amsterdam, p. 251-263

Freas, W., Grollman, S. (1980). Ionic and osmotic influence on prostaglandin release from the gill tissue of marine bivalve, Modiolus demissus. J. exp. Biol. 84: 169-185

German, B., Bruckner, G., Kinsella, J. (1983). Evidence against a $\mathrm{PGF}_{4} \alpha$ prostaglandin structure in trout tissue - a correction. Prostaglandins 26: 207-210

Goetz, F. W., Cetta, F. (1983). Ovarian and plasma PGE and PGF levels in naturally ovulating brook trout (Salvelinus fontinalis) and the effects of indomethacin on prostaglandin levels. Prostaglandins 26: 387-395

Goetz, F. W., Smith, D. C., Krickl, S. P. (1982). The effects of prostaglandins, phosphodiesterase inhibitors, and cyclic AMP on ovulation of brook trout (Salvelinus fontinalis) oocytes. Gen. Comp. Endocrinol. 48: 154-160

Goetz, F. W., Theofan, G. (1979). In vitro stimulation of germinal vesicle breakdown and ovulation of yellow perch (Perca Flavescens) oocytes: effects of 17 - $\alpha$-hydroxy-20- $\beta$ dihydroprogesterone and prostaglandins. Gen. Comp. Endocrinol. 37: 273-285

Granstrom, E., Kindahl, H. (1978). Radioimmunoassay of prostaglandins and thromboxanes. Adv. Prostaglandin Thrombox. Res. 5: 119-210

Graves, S. Y., Dietz, T. H. (1979). Prostaglandin $E_{2}$ inhibition of sodium transport in the freshwater mussel. J. exp. Zool. 210: 195-201

Jalabert, B., Szollosi, D. (1975). In vitro ovulation of trout oocytes: effect of prostaglandins on smooth muscle-like cells of the theca. Prostaglandins 9: 765-779

Joseph, J. D. (1982). Lipid composition of marine and estuarine invertebrates, Part II, Mollusca. Prog. Lipid Res. 21: 109-153

Karim, S. M. M. (ed.) (1976). Prostaglandins: chemical and biochemical aspects. University Park Press, Baltimore

Kennedy, I. (1982). Pharmacology of natural prostaglandins and analogues. In: Roberts, S. M., Newton, R. F. (ed.) Prostaglandins and thromboxanes. Butterworth Scientific, London, p. 19-36

Keuhl, F. A., Cirillo, V J., Oien, H. G. (1976). Prostaglandincyclic nucleotide interactions in mammalian tissues. In: Karim, S. M. M. (ed.) Prostaglandins: chemical and biochemical aspects. University Park Press, Baltimore, p. $191-224$

Kirton, K. T. (1977). Radioimmunoassay of prostaglandins. In: Abrahams, G. E. (ed.) Handbook of radioimmunoassay. Marcel-Dekker, Inc., New York, p. 657-677

Lands, W. E. M., Smith, W. L. (ed.) (1982). Methods in enzymology, Vol. 86, Prostaglandins and arachidonate metabolites. Academic Press, New York

Levine, L., Kobayashi, T. (1983). Detection of compounds immunologically related to arachidonic acid transformation products in extracts of invertebrates. Prostaglandins, Leukotrienes, Med. 12: 357-369

Light, R. J., Samuellson, B. (1972). Identification of prostaglandins in the gorgonian, Plexaura homomalla. Tetrahedron Lett. 59: 5185-5188

Mai, J., Goswami, S. K., Bruckner, G., Kinsella, J. E. (1981). Prostaglandin $\mathrm{c} 22 \mathrm{PGF}_{4} \alpha$ acid $(\mathrm{c} 22: 6 \mathrm{n}-3)$ by trout gill. Prostaglandins 21: 691

Morse, D. E., Duncan, H., Hooker, N., Morse, A. (1976). Proc. UN Symp. on Prog. in Caribbean Res. (CICAR-II). Caracas, July 1976

Morse, D. E., Duncan, H., Hooker, N., Morse, A. (1977).
Hydrogen peroxide induces spawning in mollusks with activation of prostaglandin endoperoxide synthetase. Science 196: 298-300

Needleman, P., Raz, A., Minkes, M. S., Ferrendelli, J. A., Sprecher, H. (1979). Triene prostaglandins: prostacyclin and thromboxane biosynthesis and unique biological properties. Proc. natn. Acad. Sci. U.S.A. 76: $944-948$

Nomura, T, Ogata, H. (1976). Distribution of prostaglandins in the animal kingdom. Biochim. biophys. Acta 431: $127-131$

Ogata, H., Nomura, T. (1975). Isolation and identification of prostaglandin $E_{2}$ from the gastrointestinal tract of shark, Triakis scyllia. Biochim. biophys. Acta 388: 84-91

Ogata, H., Nomura, T., Hata, M. (1978). Prostaglandin biosynthesis in the tissue homogenates of marine animals. Bull. Jap. Soc. scient. Fish. 44: 1367-1370

Ogata, H., Nomura, T., Hata, M. (1979). Prostaglandin $F_{2} a$ changes induced by ovulatory stimuli in the pond loach Misgurnus anguillicaudatus. Bull. Jap. Soc. scient Fish. 45: 929-931

Ono, K., Osada, M., Matsutani, T., Mori, K., Nomura, T (1982). Gonadal prostaglandin $F_{2} \alpha$ profile during sexual maturation in the oyster, Crassostrea gigas Thunberg. Mar. Biol. Lett. 3: 223-230

Roberts, S. M., Newton, R. F. (eds.) (1982). Prostaglandins and thromboxanes. Butterworth Scientific, London

Salmon, J. A., Karim, S. M. M. (1976). Methods for analysis of prostaglandins. In: Karim, S. M. M. (ed.) Prostaglandins: chemical and biochemical aspects. University Park Press, Baltimore, p. 26-85

Samuelsson, B., Granstrom, E., Green, K., Hamberg, M., Hammarstrom, S. (1975). Prostaglandins. Ann. Rev. Biochem. 44: 669-695

Schneider, W. P., Hamilton, R. D., Rhuland, L. E. (1972). Occurrence of esters of (15-S) prostaglandin $A_{2}$ and $E_{2}$ in coral. J. Am. chem. Soc. 94: 2122-2123

Singh, A. K., Singh, T. P. (1976). Effect of clomid, sexovid and prostaglandins on induction of ovulation and gonadotropin secretion in a freshwater catfish, Heteropneustes fossilis Bloch. Endokrinol. 68: 129-136

Stacey, N. E. (1976). Effects of indomethacin and prostaglandins on the spawning behavior of female goldfish. Prostaglandins 12: 113-126

Stacey, N. E. (1981). Hormonal regulation of female reproductive behavior in fish. Am. Zool. 21: 305-316

Stacey, N. E., Goetz, F. W. (1982). Role of prostaglandins in fish reproduction. Can. J. Fish. aquat. Sci. 39: 92-98

Stacey, N. E., Liley, N. R. (1974). Regulation of spawning behavior in the female goldfish. Nature, Lond. 247: 71-72

Stacey, N. E., Pandey, S. (1975). Effects of indomethacin and prostaglandins on ovulation of goldfish. Prostglandins 9: $597-607$

Stacey, N. E., Peter, R. E. (1979). Central action of prostaglandins in spawning behavior of female goldfish. Physiol. Behavior 22: 1191-1196

Travis, J. C. (1980). In: Travis, J. C. (ed.) Clinical radioimmunoassay. RIA-Ligan Assay Publ., New York, p. 105-108

Van Dorp, D. A., Beerthuis, R. K., Nugteren, D. H., Vonkeman, H. (1964). The biosynthesis of prostaglandins. Biochim. biophys. Acta 90: 204-207

Weinheimer, A. J., Spraggins, R. L. (1969). The occurrence of two new prostaglandin derivatives (15-epi-PGA $\mathrm{A}_{2}$ and its acetate methyl ester) in the gorgonian, Plexaura homomalla. Tetrahedron Lett. 59: 5185-5189 